\title{
Z B Research Square \\ Structural and Surface Modifications by Varying Precursor Concentrations on Spray Deposition of Zno Thin Films
}

\author{
Rajalekshmi ES ( $\nabla$ rajalekshmimsc@gmail.com ) \\ Scott Christian College https://orcid.org/0000-0001-9686-1646 \\ V. Anslin Ferby \\ Scott Christian College \\ R Shabu \\ Alphonsa College of Arts and Science College
}

\section{Short Report}

Keywords: Structural Analysis, ZnO, precursor concentration, optical properties, Thin films

Posted Date: September 30th, 2021

DOl: https://doi.org/10.21203/rs.3.rs-921767/v1

License: () (i) This work is licensed under a Creative Commons Attribution 4.0 International License. Read Full License 


\begin{abstract}
Zinc Oxide thin films have been deposited on glass substrates using zinc acetate as starting precursor at different concentrations $0.05-0.3 \mathrm{M}$ in steps of $0.05 \mathrm{M}$ by spray pyrolysis method at the constant substrate temperature of $350^{\circ} \mathrm{C}$. Lattice structure of the prepared ZnO films were characterized by X-Ray diffraction analysis (XRD). Diffraction pattern revealed hexagonal wurtzite structure with cell edges $a=3.2530 \AA, c=5.2092 \AA$ and density $5.66 \mathrm{~g} / \mathrm{cm}^{3}$, which is almost equal to the standard values $a=3.2556 \AA, c=$ $5.2070 \AA$ and $5.6525 \mathrm{~g} / \mathrm{cm}^{3}$ (COD No: 96-900-4180). Structural parameters such as dislocation density, lattice stress, unit cell volume, number of crystallites per unit area have been calculated and its dependency with thickness was studied. As the film thickness increases, the crystallite size also increases. Through FTIR, chemical bonds and their stretching vibrations confirmed the metal-oxide phase formation. Scanning electron microscope images showed the formation of good quality film with regularly distributed spherical shaped grains. Roughness values of the films were attained from the Atomic force microscope images. In overall observations, precursor concentration has significant effect on film thickness which in turn modified the structural, optical and morphology properties of the prepared $\mathrm{ZnO}$ thin films.
\end{abstract}

\title{
1. Introduction
}

Zinc oxide is one of the promising transparent material conducting oxides (TCOs) because of its typical properties such as thermal stability, high resistance to chemical attack, stability in hydrogen plasma, wide bad gap and large exciton binding energy of $60 \mathrm{meV}$ [1-5]. It has wide applications in transparent electrodes, gas sensors [6], light emitting diodes (LEDs) [7] laser systems, heterojunction solar cells $[5,6,8,9]$, liquid crystal displays (LCDs) [6], heat mirrors [6], multilayer photo thermal conversion systems, flat panel displays etc [1-3, 6, 10-13]. Its abundance in nature and non-toxicity [14], low dielectric constant, good photoelectric and piezoelectric activities compared with other possible materials such as ITO, $\mathrm{Cd}_{2} \mathrm{SnO}_{4}$ or $\mathrm{SnO}_{2}[4,11,15,4,16]$. $\mathrm{ZnO}$ thin films have been prepared by various methods such as RF magnetron sputtering [17], ion beam sputtering [18], molecular beam epitaxy (MBE) [19] metal organic chemical vapor deposition (MOCVD [20), pulsed laser deposition [21, 22], spray pyrolysis [3, 4, 8], hydrothermal method [23] and sol-gel process [2, 5]. ZnO thin films prepared by spray pyrolysis method have been especially paid attention owing to its advantages such as low cost [4, 16], simple deposition procedure $[6,4,9,24]$, easier composition control, regular particle shape [7], low processing temperature, easy introduction of doping elements [25] etc. The other advantage of the spray pyrolysis method is the production of large area films. Moreover, in spray pyrolysis technique, the deposition and the thickness of the films can be easily controlled over a wide range by changing the spray parameters. The spray pyrolysis technique is basically a chemical deposition technique where the most important deposition parameters are the precursors, solution concentration and deposition temperature. Many authors have described the preparation and characterization of $\mathrm{ZnO}$ thin films by spray pyrolysis with high $c$-axis preferred orientation. In this research, we deal with the influence of precursor concentration on $\mathrm{ZnO}$ thin films prepared by a simple spray pyrolysis technique under six specific conditions. Finally, the structural, phase formation, morphological properties were analyzed using X-ray diffraction (XRD) techniques (XPERT-PRO), FTIR (Thermo Electron Nicolet 5700), Scanning Electron Microscopy (SEM JEOL JSM-6390LV)) and.Varian Cary 5000 spectrometer and Atomic Force Microscope respectively.

\section{Experimental Details}

$\mathrm{ZnO}$ thin films were deposited on glass substrates for different concentrations (typically $0.05,0.1,0.15,0.2,0.25,0.3 \mathrm{M}$ ) by spray pyrolysis technique. Zinc acetate was taken as the primary precursor salt dissolved in $25 \mathrm{ml}$ ethanol and $25 \mathrm{ml}$ distilled water The substrate deposition temperature was maintained at $350{ }^{\circ} \mathrm{C}$. Compressed dry air at a pressure $0.4 \mathrm{~kg} / \mathrm{cm}^{2}$ acted as a carrier gas to transform the precursor solution into a fine mist. When the fine droplets reached the preheated substrates, solvent species were evaporated and formed the desired $\mathrm{ZnO}$ as thin nanostructures. After deposition, prepared films were characterized using different instruments for deciding the nature and quality of the film.

\section{Results And Discussion}

\subsection{Structural Analysis}


Structural properties of spray deposited $\mathrm{ZnO}$ thin films as a function of precursor concentration was analyzed using XRD. Figure 1 shows the XRD patterns of $\mathrm{ZnO}$ thin films obtained at various precursor concentrations $0.05,0.1,0.15,0.2,0.25$ and $0.3 \mathrm{M}$.

The diffraction peaks are observed at angular positions $31.73,34.42,36.22,47.51,56.53,62.83$ and 67.89 corresponding to the refraction planes (1 10 ), ( $\left.\begin{array}{lll}0 & 0\end{array}\right),\left(\begin{array}{lll}0 & 1 & 1\end{array}\right),\left(\begin{array}{lll}0 & 1 & 2\end{array}\right)\left(\begin{array}{lll}1 & 1 & 0\end{array}\right)\left(\begin{array}{lll}0 & 1 & 3\end{array}\right)$ and $\left(\begin{array}{lll}1 & 1 & 2\end{array}\right)$ respectively. These peaks are indexed based on the Crystallographic Open Database, COD (96-900-4180). The $\left(\begin{array}{lll}0 & 0 & 2\end{array}\right)$ and $\left(\begin{array}{lll}1 & 0 & 1\end{array}\right)$ peaks of the ZnO films prepared using $0.05 \mathrm{M}$ solution are less intense. When the molarity is increased to $0.1 \mathrm{M}$, the peaks corresponding to the planes (1 $\left.\begin{array}{lll}1 & 2\end{array}\right),\left(\begin{array}{lll}1 & 1 & 0\end{array}\right)$ and $\left(\begin{array}{lll}1 & 0 & 3\end{array}\right)$ are observed well. Further increase to $0.3 \mathrm{M}$ results intense peaks in all planes observed before. Predominantly crystallites are oriented alone the $\left(\begin{array}{ll}0 & 0\end{array}\right)$ because the number of $\mathrm{Zn}^{2+}$ ions incorporation and growth rate $[5,26]$. It is observed that the intensity of $\left(\begin{array}{ll}0 & 0\end{array}\right)$ peak increased with increasing precursor concentration, indicating their higher crystallinity. The peak intensity is high for solution concentration of $0.3 \mathrm{M}$, showing the influence of precursor molarity on surface (orientation) of the ZnO films [2]. Thickness of the film also increases with increasing precursor concentration, $0.18 \mu \mathrm{m}, 0.94 \mu \mathrm{m}, 1.18 \mu \mathrm{m} ; 1.21 \mu \mathrm{m} ; 2.51 \mu \mathrm{m}$, and $2.75 \mu \mathrm{m}$ for the precursor concentrations $0.05,0.1,0.15,0.2,0.25$ and $0.3 \mathrm{M}$ respectively. The similar trend has been observed by J.L. van Heerden for $\mathrm{ZnO}$ fimls prepared using the same technique [27].

The crystallographic parameters like lattice constant ( $a$ and c), unit cell volume, crystallite size, microstrain, dislocation density and number of crystallites per unit area $(\mathrm{N})$ are calculated from the $2 \theta$ position of $\left(\begin{array}{lll}0 & 0\end{array}\right)$ plane and are tabulated in Table 1.

Table 1

Calculated lattice parameters of $\mathrm{ZnO}$ thin films deposited using precursors of different concentrations

\begin{tabular}{|c|c|c|c|c|c|c|c|c|c|}
\hline \multirow[t]{2}{*}{$\begin{array}{l}\text { Precursor } \\
\text { Concentration }\end{array}$} & \multicolumn{2}{|c|}{$\begin{array}{l}\text { Lattice } \\
\text { Parameter }(\AA)\end{array}$} & \multirow{2}{*}{$\begin{array}{l}\text { Unit } \\
\text { Cell } \\
\text { Volume } \\
(\AA))^{3}\end{array}$} & \multirow{2}{*}{$\begin{array}{l}\text { Crystallite } \\
\text { Size (nm) } \\
\left(\times 10^{-9}\right)\end{array}$} & \multirow{2}{*}{$\begin{array}{l}\text { Microstrain } \\
\left(\times 10^{-4}\right)\end{array}$} & \multirow{2}{*}{$\begin{array}{l}\text { Dislocation } \\
\text { Density } \\
\left(\times 10^{14}\right) \\
\text { Lines } / m^{2}\end{array}$} & \multirow{2}{*}{$\begin{array}{l}\text { Thickness } \\
(\mu \mathrm{m})\end{array}$} & \multirow{2}{*}{$\begin{array}{l}\text { No of } \\
\text { Crystallites } \\
\left(\times 10^{14}\right)\end{array}$} & \multirow{2}{*}{$\begin{array}{l}\text { Density } \\
\left(\mathrm{g} / \mathrm{cm}^{3}\right)\end{array}$} \\
\hline & a & c & & & & & & & \\
\hline $\begin{array}{l}\text { Standard } \\
\text { Value }\end{array}$ & 3.2530 & 5.2070 & 47.72 & & & & & & 5.66 \\
\hline $0.05 \mathrm{M}$ & 3.2478 & 5.2146 & 47.63 & 40.276 & 8.203 & 6.1645 & 0.8 & 4.93 & 5.6738 \\
\hline $0.1 \mathrm{M}$ & 3.2517 & 5.211 & 47.71 & 40.273 & 8.2024 & 6.1655 & 0.94 & 5.79 & 5.6641 \\
\hline $0.15 \mathrm{M}$ & 3.2555 & 5.2093 & 47.80 & 40.272 & 8.2022 & 6.1658 & 1.18 & 7.27 & 5.6527 \\
\hline $0.2 \mathrm{M}$ & 3.2556 & 5.2092 & 47.81 & 40.274 & 8.2026 & 6.1652 & 1.21 & 7.45 & 5.6525 \\
\hline $0.25 \mathrm{M}$ & 3.2569 & 5.2058 & 47.82 & 53.6932 & 6.15133 & 3.4686 & 2.51 & 8.7 & 5.6517 \\
\hline $0.3 \mathrm{M}$ & 3.2581 & 5.204 & 47.84 & 53.6931 & 6.15132 & 3.4687 & 2.75 & 9.53 & 5.6494 \\
\hline
\end{tabular}

It was found that the lattice constants, crystallite size, unit cell volume, microstrain, dislocation density and density changes with increasing precursor concentration. Obtained lattice parameter, unit cell volume and density values are similar to previously reported values by Aryanto et al [28]. Attained crystallite size of $\mathrm{ZnO}$ thin films is around $40 \mathrm{~nm}$ for the film deposited using $0.05 \mathrm{M}$ solution which increased to $53 \mathrm{~nm}$ when the precursor concentration is to $0.3 \mathrm{M}$. The crystallite size values of $\mathrm{ZnO}$ thin films increasing with increasing precursor concentration, because of the electrostatic interaction between the solute particles and also due to thickness [29]. In contrast to the crystallite size tendency, the values of strain decrease with increasing precursor concentration. This may come from the retarded crystal growth due to the stretched lattice that can increase the lattice energy and diminishes the driving force of the growth [38]. Similarly dislocation density ( $\delta$ ) values decrease as the precursor concentration increases. The obtained results are in well agreement with previous reported results [2]. Adel H. Omran Alkhayatt et al. also reported the dislocation density value of $\mathrm{ZnO}$ films as nearer to of $10^{14}$ lines / $\mathrm{m}^{2}$ [31].

\subsection{Metal-oxide phase Analysis - FTIR}


FTIR spectrum provides the information about the presence of various functional groups and the elemental constituents in the material. Figure 2 shows series of absorption peaks in the range of $400 \mathrm{~cm}^{-1}$ to $4000 \mathrm{~cm}^{-1}$, attributed to different groups and chemisorbed species in $\mathrm{ZnO}$ thin films prepared using precursors of different concentration.

Table 2

Vibrational Frequencies of $\mathrm{ZnO}$ Compounds

\begin{tabular}{|lll|}
\hline $\begin{array}{l}\text { Wavenumber }\left(\mathrm{cm}^{-1}\right) \\
\text { Reported values }\end{array}$ & $\begin{array}{l}\text { Wavenumber }\left(\mathrm{cm}^{-1}\right) \\
\text { Present study }\end{array}$ & Assignment \\
\hline 505 & 471 & ZnO Streching \\
1632 & 1640 & O-H deformation \\
3465 & 3450 & O-H stretching \\
\hline
\end{tabular}

The peak at $471 \mathrm{~cm}^{-1}$ due to the stretching vibrations of $\mathrm{Zn}-\mathrm{O}$ bonds which confirmed the formation of $\mathrm{ZnO}$ [3]. A broad peak at $3460 \mathrm{~cm}^{-1}$ which matches to the vibration mode of $\mathrm{O}-\mathrm{H}$ bond indicated the coordination with hydroxide. This may be due to absorption of moisture as imperfection content [32]. One more peak at $1641 \mathrm{~cm}^{-1}$ was due to deformation vibration of $\mathrm{H}_{2} \mathrm{O}$ or $\mathrm{O}-\mathrm{H}$ group.

\subsection{Morphological studies}

Surface morphology of the ZnO thin films deposited with various precursor concentration was recorded in SEM. Figure 3 shows SEM images of ZnO thin films recorded at the magnification of 80,000.

As observed, precursor concentration and thickness of the film has dominant effect on surface morphology of films. It is observed from the SEM images, all the ZnO films exhibit smooth and spherical grain structure. Many researchers reported $\mathrm{ZnO}$ films with spherical like structures by changing temperature, concentration and dopant ratio [26, 33]. For the film deposited with precursor concentration $0.05 \mathrm{M}$ the average diameter of the spherical structures is $0.18 \mu \mathrm{m}$, when the film precursor concentration is increased to $0.3 \mathrm{M}$, the diameter of the spherical grains are increased to $0.98 \mu \mathrm{m}$. Hence the surface morphology modifies according to precursor concentration of the films. As precursor concentration increases, gradual evolution of the grain size and shape. Similar observations were reported by Vinoth Kumar Jayaraman et al [34]. These variations will surely alter the physical and chemical properties. The overall nature reveals a continuous film on the substrate surface without holes or cracks with smooth and the substrates are fully covered with material.

Atomic force microscopy (AFM) 2D and 3D images of the ZnO thin films have been recorded for two ZnO films prepared using precursor concentrations $0.2 \mathrm{M}$ and $0.3 \mathrm{M}$. Figure 4 shows the columnar structure, which is contrast from SEM images.

The crystallite size seems to be increased with increasing precursor concentrations. AFM investigations show is smooth and homogeneous. Surface roughness values are found in the range from $22 \mathrm{~nm}$ to $61 \mathrm{~nm}$. The surface roughness increased with the increasing precursor concentrations. The values of the grain size calculated using AFM were found to be $75.8 \mathrm{~nm}, 80.8 \mathrm{~nm}$ for the films deposited using of different concentration precursors $0.2 \mathrm{M}$ and $0.3 \mathrm{M}$ respectively. Particle size obtained from AFM analysis are far higher than crystallite size obtained from XRD. Similar results were reported by Chaithra et al [35].

\subsection{Conclusion}

$\mathrm{ZnO}$ thin films were successfully synthesized by spray-pyrolysis method using precursors of different concentrations. Spray system with optimized deposition condition allowed obtain $\mathrm{ZnO}$ films. Prepared samples were wurtzite hexagonal structured and their mean particle sizes and crystallinity were gradually improved on increasing morality. The structural, optical properties of the ZnO thin films have been found to be influenced by precursor concentration during deposition. XRD studies revealed improved crystalline character on by increasing the precursor concentration. The ZnO phase formation was also identified from the FTIR studies. The crystalline quality of the films gets better and the grain size increases as the precursor concentration increases. The high resolution FE-SEM 
images showed uniform distribution of spherical grain. Surface roughness parameter determined by AFM imaging increases from $22 \mathrm{~nm}$ to $61 \mathrm{~nm}$ for increasing precursor concentration.

\section{References}

1. S. Acharya, S.K. Biswal, S.N. Sarangi, 2019, Effect of Structure and Morphology on the UV Photo Detection of ZnO Nanostructures and Microstructures, Chemical Physics, 523, 99-105

2 M. Soylu, M.Coskun, 2018, Controling the properties of ZnO thin films by varying precursor concentration, Journal of Alloys and Compounds, 741, 957-968

3. Tatjana Dedova, Ilona Oja Acik, Svetlana Polivtseva, Malle Krunks, Inga Gromyko, Kaia Tonsuaadu, Arvo Mere, 2019, Influence of solution composition on sprayed $\mathrm{ZnO}$ nanorods properties and formation process: thermoanalytical study of the precursors, ceramics international 45, 2887-2892

4. E. Bacaksiz, M. Parlak, M. Tomakin, A. Ozc, elik, M. Karakız, M. Altunbas, 2008, The effects of zinc nitrate, zinc acetate and zinc chloride precursors on investigation of structural and optical properties of $\mathrm{ZnO}$ thin films, Journal of Alloys and Compounds 466, 447-450

5. Yi Chen, Jyoti Nayak, Hyun-UKo, JaehwanKim, 2012, Journal of Physics and Chemistry of Solids, Journal of Physics and Chemistry of Solids $73,1259-1263$

6 P. Nunesa, E. Fortunatoa, P. Vilarinhob, R. Martinsa, 2001, Effect of different dopants on the properties of ZnO thin films, International Journal of Inorganic Materials $3,1211-121321$

7. Sang Duck Lee, Sang-Hun Nam, Myoung-Hwa Kim and Jin-Hyo Boo, 2012, Synthesis and Photocatalytic Property of ZnO nanoparticles Prepared by Spray-Pyrolysis Method, Physics Procedia, 32, 320 - 326

8. R. Ayouchia, F. Martinb, D. Leinena, J.R. Ramos Barradoa, 2003, Growth of pure ZnO thin films prepared by chemical spray pyrolysis on silicon, Journal of Crystal Growth 247, 497-504

9. M.T. Mohammada, A.A. Hashimb, M.H. Al-Maamoryc, 2006, Highly conductive and transparent ZnO thin films prepared by spray pyrolysis technique Materials Chemistry and Physics, 99, 382-387

10. K.I. Mohammed, F.M. Jasim, M.I. Azawe, 2014, Influence of thickness and crystalline structure on thermal and optical properties of ZnO thin films, Current Applied Physics $14,318-1324$

11. U. Srinivasa Raoa, G. Srinivasb and T. Prasada Raoc, 2015, Influence of precursors on morphology and spectroscopic properties of ZnO Nanoparticles Procedia Materials Science 10, 90 - 96

12. Z.X. Yu, Y.Z. Ma, Y.L. Zhao, J.B. Hang, W.Z. Wang, M. Moliere, H.L. Liao, 2017, Effect of precursor solutions on ZnO film via solution precursor plasma spray and corresponding gas sensing performances, 412, 683-689

13. C.K. Zagal-Padilla, S.A. Gamboa, 2018, Optoelectronic Characterization of ZnO obtained by Green Synthesis of Zn-salt precursor in parsley extract, Journal of Alloy and Compounds, 767, 932-937

14. C.S. Prajapati, P.P. Sahay, 2013, Influence of In doping on the structural, optical and acetone sensing properties of ZnO nanoparticle thin films, Materials Science in Semiconductor Processing 16, 200-210

15 B. Bhushan a, B.S. Murty b, K. Mondal a, 2018, A new approach for synthesis of ZnO nanorod flowerets and subsequent pure free-standing ZnO nanorods, Advanced Powder Technology, 30, 30-41

16. A. Bougrine, A. El Hichou, M. Addoua,, J. Ebothe, A. Kachouane, M. Troyon , 2003 Structural, optical and cathodoluminescence characteristics of undoped and tin-doped $\mathrm{ZnO}$ thin films prepared by spray pyrolysis Materials Chemistry and Physics $80,438-445$ 
17. M.R. Alfaro Cruz, O. Ceballos Sanchez, E. Lu evano Hip olito, L.M. Torres-Martınez, 2018, ZnO thin films deposited by RF magnetron sputtering: Effects of the annealing and atmosphere conditions on the photocatalytic hydrogen production, International Journal of Hydrogen Energy, 43, 10301-10310

18. Hung-Yin Tsai, 2007, Characteristics of ZnO thin film deposited by ion beam sputter, Journal of Materials Processing Technology, 192, 55-59

19. Giwoong Nam, Jae-Young Leem, 2017, Fast-response photoconductive ultraviolet light detectors fabricated using high-quality ZnO films obtained by plasma-assisted molecular beam epitaxy Ceramics International, 43, 1981-11985

20. Jian Lia,b , Jie Wanga , Yanli Peia,b , Gang Wanga,b, 2019, Study on the uniformity of ZnO films grown by MOCVD, Vacuum, 45, 13971-13978

22. Jaroslav Bruncko, Pavol Sutta, Marie Netrvalova, Miroslav Michalka, Andrej Vincze,2019, Pulsed laser deposition of Ga doped $\mathrm{ZnO}$ films - Influence of deposition temperature and laser pulse frequency on structural, optical and electrical properties, Vacuum, $159,134-140$

23. P. Soundarrajan, K. Sankarasubramanian, T. Logu, K. Sethuraman, ArunavaGupta, S.M. Senthil Kumar, K. Jeganathan, K. Ramamurthi, 2019, The degree of supersaturation dependentt ZnO nano/micro rod arrays thin films growth using chemical bath deposition and hydrothermal methods, Physica E: Low dimensional Systems and Nanostructures, 106, 50-56

24. Saeed Rahemi Ardekani, Alireza Sabour Rouh Aghdam, Mojtaba Nazari, Amir Bayat, Elnaz Yazdani Esmaiel Saievar Iranizad, 2019, A comprehensive review on ultrasonic spray pyrolysis technique: Mechanism, main parameters and applications in condensed matter, Journal of Analytical and Applied Pyrolysis, 141, 104631

25. S. Edinger, J. Bekacz, M. Richter, R. Hamid, R.A. Wibowo, A. Pei, T. Dimopoulos, 2015, Influence of the acetic acid concentration on the growth of zinc oxide thin films prepared by spray pyrolysis of aqueous solutions Thin Solid Films, 594, 238-244

26. F.K. Konan, J.S. N'cho, H.J. Tchognia Nkuissi, B. Hartiti, A. Boko,2019, Influence of the precursor concentration on the morphological and structural properties of zinc oxide (ZnO), Material Chemistry and Physics, 229, 330-333

27. J.L. van Heerden U, R. Swanepoel, 1997, XRD analysis of ZnO thin films prepared by spray pyrolysis,Thin Solid Films, 299, 7277

28. D Aryanto, W N Jannah, Masturi, T Sudiro, A S Wismogroho, P Sebayang, Sugianto and P Marwoto, 2017, Preparation and structural characterization of ZnO thin films by sol-gel method, Journal of Physics: Conference Series, 817, 012-025

29. R. Amari A. Mahroug, A. Boukhari, B. Deghfel, N. Selmi, 2018, Structural, Optical and Luminescence Properties of ZnO Thin Films Prepared by Sol-Gel Spin-Coating Method: Effect of Precursor Concentration, Chinese.Physics Letter, 35, 016-801

30. R. Ghosh, D. Basak, and S. Fujihara, 2004, Effect of substrate-induced strain on the structural, electrical, and optical properties of polycrystalline ZnO thin films, Journal of Applied Physics, 96, 2689

31. Adel H. Omran Alkhayatta, 2017, Shymaa K. Hussianb Fluorine dopant concentration effect on the structural and optical properties of spray deposited nanocrystalline ZnO thin films, Surfaces and Interfaces, 8, 176-181

32. Mehrnaz Gharagozlou Sanaz Naghibi, 2016, Sensitization of ZnO nanoparticle by vitamin B12: Investigation of microstructure, FTIR and optical properties, Material Research Bulletin, 84, 71-78

33. C. Cachoncinlle C. Hebert J. Perri'ere M. Nistor A. Petit E. Millon, 2014, Random lasing of ZnO thin films grown by pulsed-laser Deposition, Applied Surface Science, 169, 288-292

34. Vinoth Kumar Jayaraman, Agileo Hernández-Gordillo1, Monserrat Bizarro, 2018, Importance of precursor type in fabricating ZnO thin films for photocatalytic Applications, Materials Science in Semiconductor Processing 75, 36-42 
35. U. Chaitra, Dhananjaya Kekuda, K Mohan Rao, 2017, Effect of annealing temperature on the evolution of structural, microstructural, and optical properties of spin coated ZnO thin films, Ceramics International 43, 7115-7122

\section{Figures}

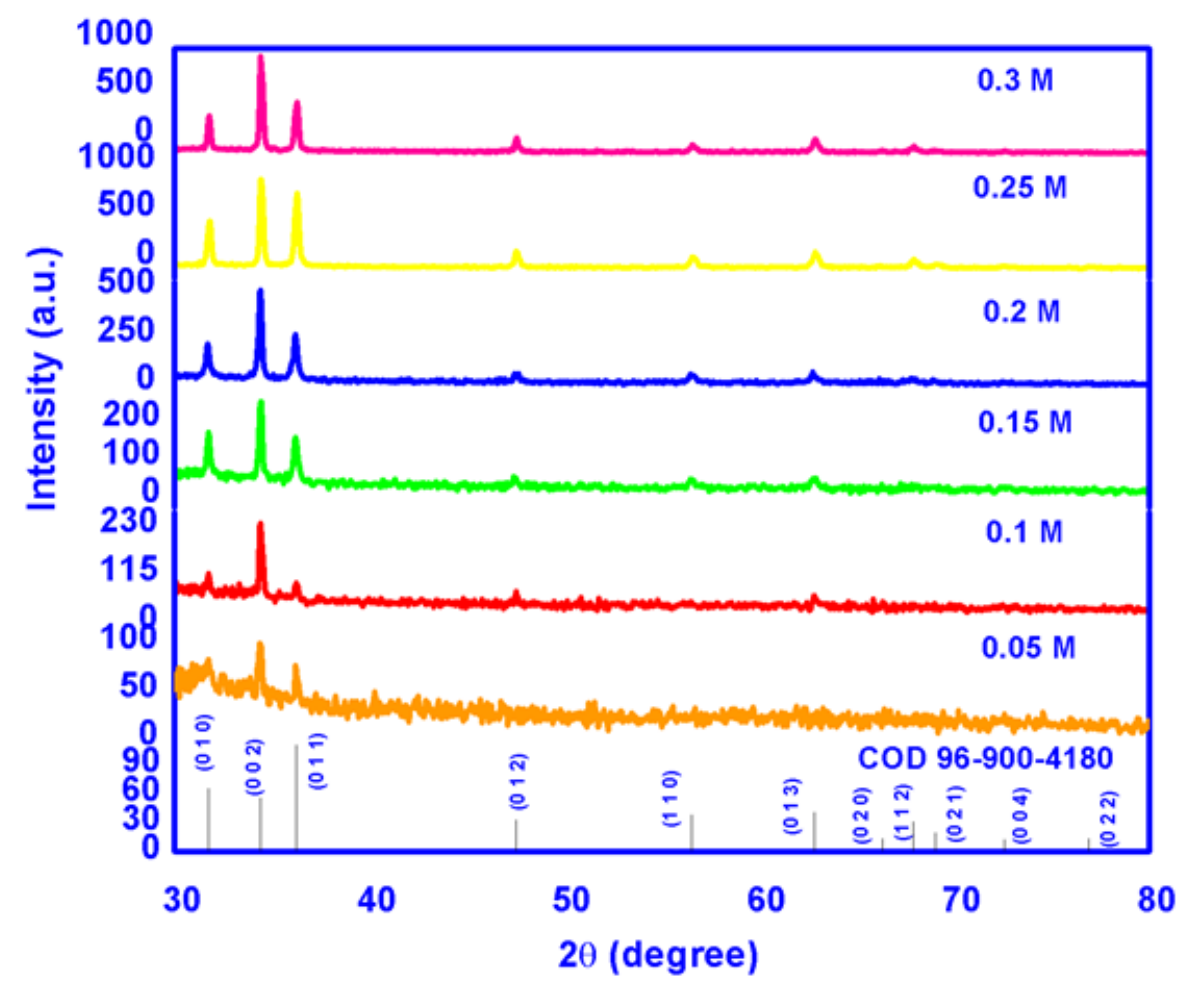

Figure 1

XRD patterns of ZnO thin films deposited using precursors of different concentrations.

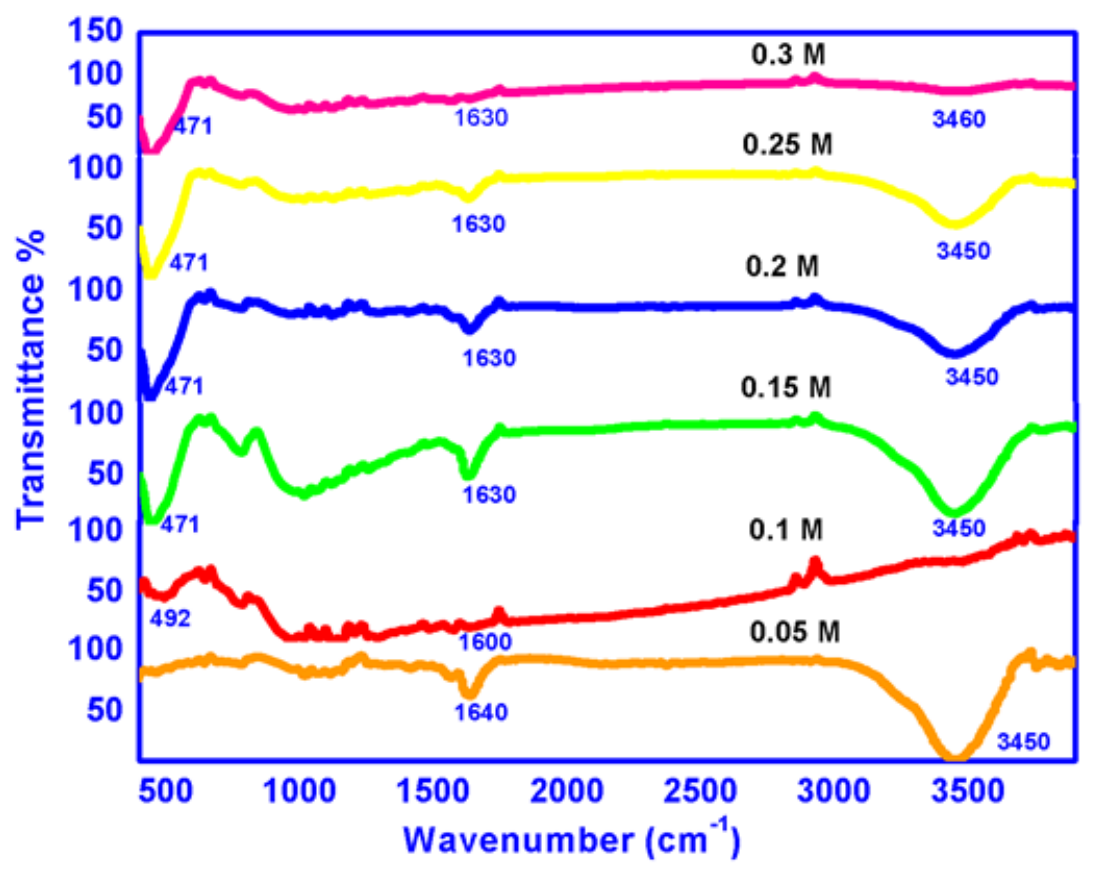

Figure 2 
FTIR spectrum of $\mathrm{ZnO}$ thin films deposited using precursors of different concentrations.

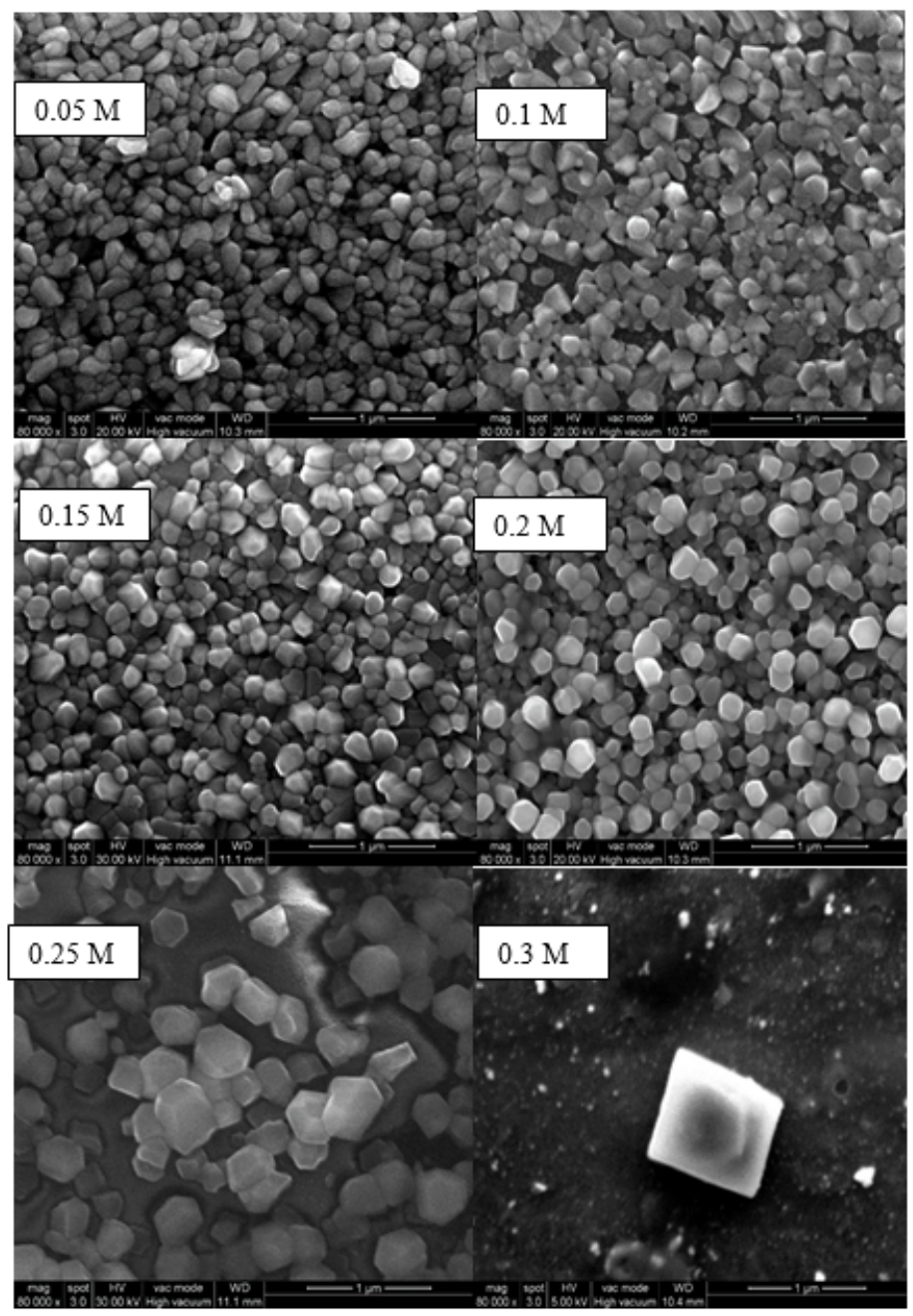

Figure 3

SEM micrographs of $\mathrm{ZnO}$ thin films prepared using precursors of different concentrations. 

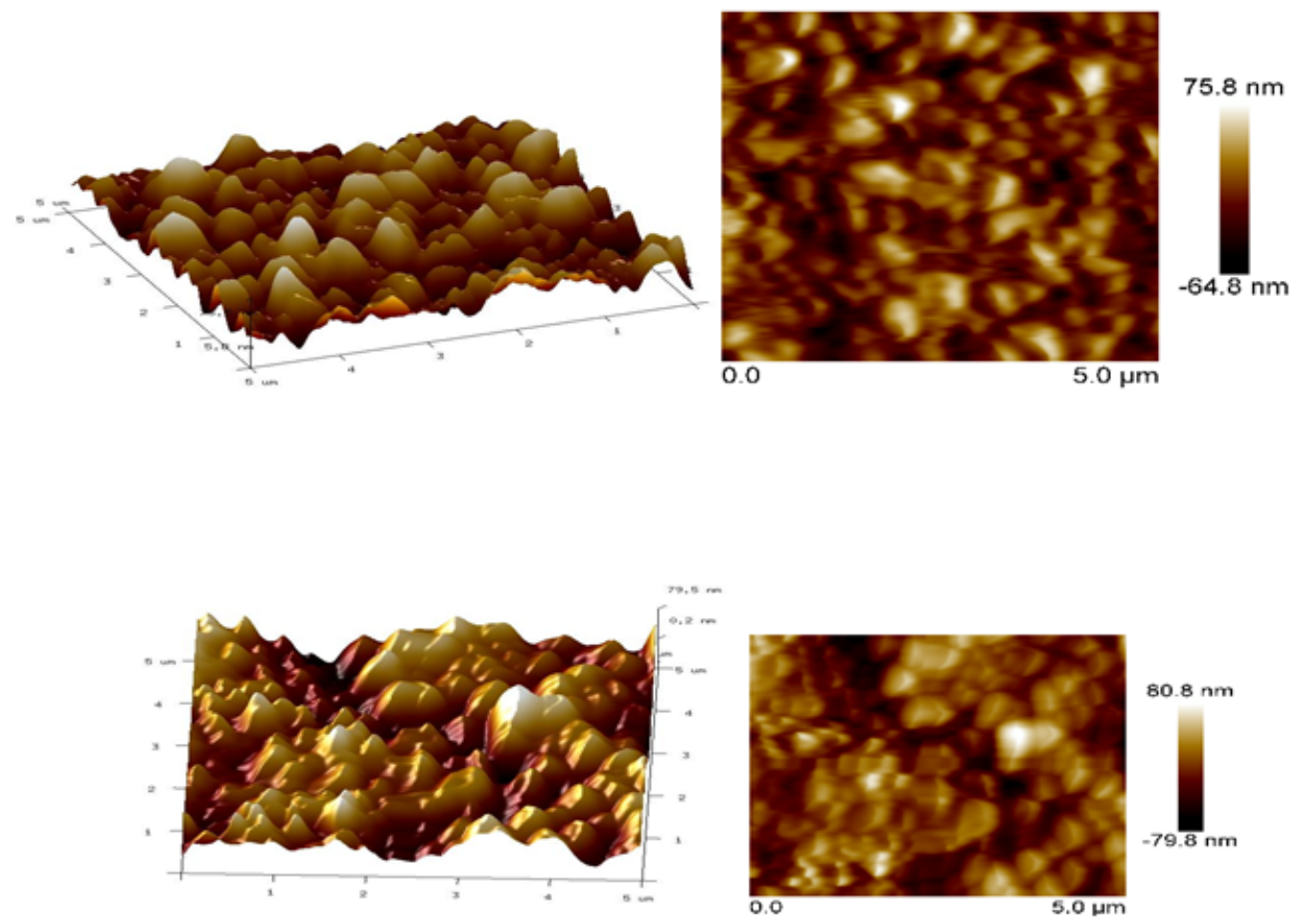

Figure 4

AFM images of $\mathrm{ZnO}$ thin films prepared using precursors of different solution concentrations. 